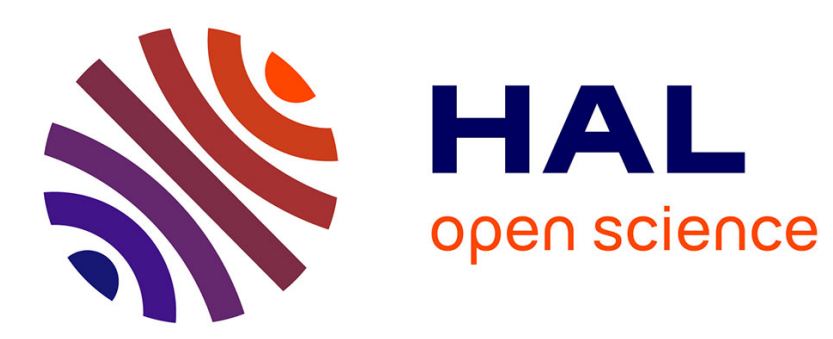

\title{
Impact of climatic variations on bird species occupancy rate in a southern European forest
}

Florent Bled, Jean Joachim, Jérôme Dupuis

\section{To cite this version:}

Florent Bled, Jean Joachim, Jérôme Dupuis. Impact of climatic variations on bird species occupancy rate in a southern European forest. Biodiversity and Conservation, 2011, 20 (6), pp.1203-1224. 10.1007/s10531-011-0023-2 . hal-01011145

\section{HAL Id: hal-01011145 \\ https://hal.science/hal-01011145}

Submitted on 25 Jun 2014

HAL is a multi-disciplinary open access archive for the deposit and dissemination of scientific research documents, whether they are published or not. The documents may come from teaching and research institutions in France or abroad, or from public or private research centers.
L'archive ouverte pluridisciplinaire HAL, est destinée au dépôt et à la diffusion de documents scientifiques de niveau recherche, publiés ou non, émanant des établissements d'enseignement et de recherche français ou étrangers, des laboratoires publics ou privés. 


\section{IMPACT OF CLIMATIC VARIATIONS ON BIRD SPECIES} 2 OCCUPANCY RATE IN A SOUTHERN EUROPEAN FOREST

4 BLED Florent ${ }^{1}{ }^{1 *}$, JOACHIM Jean $^{2}$, DUPUIS Jérôme ${ }^{3}$

5

$6 \quad{ }^{1}$ Laboratoire Evolution et Diversité Biologique, Université Paul Sabatier, France

$7 \quad 2$ INRA-CEFS, BP 27, 31326, Castanet-Tolosan, Toulouse, France

$8 \quad{ }^{3}$ Laboratoire de Statistique et Probabilités, Université Paul Sabatier, Toulouse, France

$9 *$ Corresponding author (phone: +33.6.63.15.47.58, fax: +33.5.61.55.73.27, e-mail: 10 bled@cict.fr) 
Occupancy rate modeling for bird species undergoing climatic changes

\section{Abstract}

2 Species that are affected by climatic variations can undergo modification in range and/or 3 abundance. Knowing how individuals or species occupy their habitat is essential to

4 understand how species use their environment, and detecting variations that might affect this 5 use can be determinant in species management.

6 Hierarchical modeling is regularly used to assess for occupancy rate (i.e. proportion of 7 patches occupied in a region), particularly when it is required to consider detectability-related 8 issues. The present study is the first application of the conditional model presented in Dupuis 9 et al. (2010), and which is applied in the case of a heterogeneous area that might be divided into homogeneous sub-areas. Their approach is used to study the impact of three consecutive 11 particularly cold winters on a selected set of bird species in a forest of southern France in the context of available prior information on birds detectability.

We examined a limited range of factors that might influence the response of some bird 14 species to climatic. We considered the case of sedentary, partially migrating and migrating species. We also assessed if the biogeographical origins of the different species affect their occupancy rates. Globally, changes in occupancy rates between 1985 and 1987 indicates for the first time a continentalization of the regional forest fauna, reflected by the expansion of Palearctic and Turkestano-european faunistic type species, with depletion or extinction of European, Turkestano-mediterranean and Mediterranean sedentary species. We have also shown the importance of prior information. information. 
Occupancy rate modeling for bird species undergoing climatic changes

\section{Introduction}

2 Two of direct effects of climate change that species will likely have to face are an increase

3 in mean temperature) (e.g. Malcom et al., 2006) and an increased in the frequency of extreme

4 temperatures (e.g. Colombo et al., 1999). Species' responses to these climatic changes may

5 include evolution or adaptation, modification in range and abundance, or extinction (Ackerly,

62003 ; Parmesan, 2006).

7 Most of the examples of rapid adaptation to climate change lie in evolution toward higher

8 frequencies of already existing heat-tolerant genotypes in the interiors of species' ranges

9 (Parmesan, 2006). While adaptation can occur after a significant amount of time, for punctual

10 variation of the climate, migration and extinction are more likely (Huntley, 1991 ; Davis \&

11 Zabinski, 1992 ; Coope, 1994). Extinction or increased risk of extinction due to climatic

changes have been documented in a wide range of taxa such as amphibians (Pounds et al., 1999, 2005), tropical corals (Hoegh-Guldberg 1999; Wilkinson 2000), mammals (e.g. Arctic polar bears, Derocher ; 2005, Stirling et al. 1999) and birds (e.g. Antarctic Adélie Penguins, Ainley et al., 2003 ; Croxall et al., 2002). In fact, if an unusual variation in temperature occurs, such as a significantly colder winter, species that are not adapted to cold temperature and that have not migrated might have to undergo extreme conditions and potentially go locally extinct. Range shifts are expected to occur poleward and upward. Several species of Lepidoptera (butterflies and moths) have undergone an expansion of northern boundaries situated in Finland (Mikkola, 1997), Great Britain (Hill et al., 2002), and across Europe

21 (Parmesan et al., 1999). Some bird species have been shown to have a northern shift of their range boundaries (Thomas \& Lennon, 1999). Some species have even shown elevational

23 shifts in response to climate changes (e.g. lowland birds, Pounds et al., 1999, 2005 ; alpine 24 flora, Grabherr et al., 1994, Pauli et al., 1996). 
In this context, understanding how individuals or species occupy their habitat and use their

2 environment (Krebs, 1978) will be essential to predict population response to extreme

3 climatic conditions and take suitable management dispositions (Kendall, 2001; Williams et al.,

42002 ; Nichols, 2004 ; MacKenzie et al., 2006). Site occupancy modeling has been

5 thoroughly developed during the last decade, leading to powerful methods to estimate site

6 occupancy, which in turn allows estimation of population parameters such as colonization and

7 extinction probabilities. These models have proven to be reliable for common ecological data

8 (i.e. detection-non detection), and when the area of interest is large (such as a country) or

9 relatively small (e.g. a forest), or when the considered area is divided in an important number

10 of quadrat (i.e. sub-unit of the global area that might be sampled) or not.

11 Site occupancy rate is one of the key variables for determining how species use their environment. While density and abundance carry information on the population state, occupancy rate describes how species use the spatial environment they live in. It is defined as the proportion of patches occupied and is a state variable in various metapopulations models (e.g., Levins, 1969, 1970 ; Lande, 1988 ; Hanski, 1997). Site occupancy rate by definition has to be considered in a 'closed environment', i.e. with a finite number of locations (termed sites or quadrats). While this has been well studied when there is a large number of sites, improvements are still needed when the number of sites is small (MacKenzie et al., 2006).

Estimating occupancy rate using hierarchical modeling allows accommodation of issues related to detectability. We now can account for the fact that when a species is not detected it

21 could correspond to an effective absence or just a failure in detection. Modifications of the 22 original approach of MacKenzie et al. (2002) allowed for a more accurate estimation of occupancy rate in the specific case of a small homogeneous area with a small total number of quadrats (e.g. MacKenzie et al., 2006) or when species are particularly hard to detect (Dupuis et al., 2010). This difficulty in detection can emerge from individual's characteristics (e.g. 
Occupancy rate modeling for bird species undergoing climatic changes

1 cryptic abilities) or simply because a species has a low presence probability, which is typical

2 of endangered species.

3 Here, we apply the conditional model presented in Dupuis et al. (2010) to the case of a

4 heterogeneous area that can be divided into homogeneous sub-areas (e.g. edge and inner part

5 of a forest). One of the main characteristics of this model is that it uses a conditional approach

6 for estimating the quantity of interest (here, occupancy rate); conditioning bearing on the

7 presence of target species in the region of study. The unconditional approach (MacKenzie $e t$ al., 2006) does not presuppose that the target species is present in the whole region of interest.

9 Conditional approach has been proven to be a necessary approach in the case of undetected species which are known to be present in the area from another source of information (such as net capture) (Dupuis et al., 2010). Moreover, we shall take advantage of that some prior information on detectability is available, since it is expected that this significantly improves the precision of estimates when the target species has been very few or not detected, and is known to be easily detectable (Dupuis et al., 2010). The data used in this study present several such examples. Furthermore, in each instance where a species is not detected in our dataset it is known from external sources that it was in fact present in the study area.

We focus on several factors that might influence the response of bird species to climatic changes (here the succession of three significantly colder winters). First, occupancy rate in the inner forest might be less affected by the decrease in temperature than in the edge of the forest because more protection is available for individuals. Evolution of occupancy rates might be 21 crucially different between the external and the inner parts of a forest. For example, species can have preferences into one or the other part, and if no distinction is made between these regions, one could not see a modification of occupancy. Second, we compare sedentary, partially migrating and migrating species. We expect migratory species occupancy rate to be less impacted by cold winters than that of sedentary species, because they are not directly 
Occupancy rate modeling for bird species undergoing climatic changes

1 affected by local low temperatures at reproduction sites. Specifically, we predict sedentary

2 species' occupancy rate to decrease. Third, we compare species with different bioclimatic

3 affiliations which illustrate tolerance of a species to cold. We predict that species with a more

4 continental bioclimatic affiliation will not experience a dramatic decrease in occupancy rate

5 compared to other species. Finally; in the discussion, each of the conclusions resulting from

6 this local application will be examined in the light of what happened at the continental scale.

7

8

$9 \quad$ Material \& Methods

10 Location - We focus on data collected in May 1985 and May 1987 in order to estimate occupancy rates of nesting bird species present in the Montech forest (located near Toulouse, France), and the impact of 3 successive particularly cold winters. Montech forest has an area of 900ha and is part of the French National Forest System (Office National des Forêts). While this forest has a mixed management regime of mature and coppiced forest, it is now only managed as a mature forest The forest is dominated by oak species (Quercus robur, Quercus sessiliflora and Quercus pubescens). The undergrowth is composed of hawthorns (Crataegus), blackthorns (Prunus spinosa), brooms (Fabaceae), and heaths (Erica). Some Coast Douglasfirs (Pseudotsuga menziesii) and Maritime Pines (Pinus pinaster) plots are present in the south part of this forest. The study area is proximate to continental, Mediterranean, alpine and Atlantic ecoprovince (fig.1).

Data are a part of a broad study of bird populations in the Midi-Pyrénées region of southwest France. Data collection began in 1985 (Joachim et al., 1997). Montech forest underwent 3 colder-than-usual winters in 1985, 1986 and 1987. During these winters, mean monthly temperatures dropped up to $5^{\circ} \mathrm{C}$ below the average monthly temperature of 14 
Occupancy rate modeling for bird species undergoing climatic changes

1 previous years, and $3^{\circ} \mathrm{C}$ below the coldest temperatures during this reference period (Fig. 2).

2 These three winters correspond to a hinge period. In contrast, from 1965 to 1985 , winters

3 were fairly mild. Empirical observations suggest that these mild temperatures led to a

4 colonization of Mediterranean and a retreat of continental bird species. The exceptional 1985-

51987 period contrasted strongly and that likely impacted the fauna potentially leading to a

6 strong re-continentalization. While species might easily overcome one colder than usual

7 winter, the succession of 3 cold winters on end can be expected to have consequences for bird 8 species.

9

Data and species list - We focus on to the estimation of occupancy rate and detection probabilities of 10 bird species of the overall 47 detected species. The list of the species of interest is denoted by $\mathcal{L}$. Here, the list of chosen bird species, liable to be present in the forest of Montech, in spring 1985 and 1987 includes 10 species: whitethroat, chiffchaff, nightingale (which are migratory species), Eurasian nuthatch, green wood pecker, short-toed treecreeper (which are sedentary species), and finally song thrush, common blackbird, European robin, mistle thrush (which are partial migrants). Partial migrant species are species with overlapping reproductive and wintering areas. Migratory status and biogeographical origins are presented in table 2. Moreover, for each species, prior information on detection 19 probability is available (tab. 3).

Montech forest, with a surface area of 900 hectares has been divided into $A$ homogeneous subregions of biological interest, here $A=2$ with the two sub-regions being the inner forest $23(a=1)$ and the edge forest $(a=2)$. A sampling is performed in each sub-region $R_{a}$. The sub24 region $R_{a}$ is divided into $J_{a}$ spatial units, here termed quadrats. They are also called sites in 25 the literature. A subset of $T_{a}$ quadrats is sampled. Draw is usually performed at random so as 
Occupancy rate modeling for bird species undergoing climatic changes

1 to have a sample representative of the whole region $R_{a}$. We assume that these quadrats are of

2 equal area. Twenty-two quadrats are located in the inner forest $\left(\mathrm{J}_{1}=22\right)$, while 18 quadrats

3 correspond to forest's edges $\left(\mathrm{J}_{2}=18\right)$. In 1985, all quadrats were sampled $\left(\mathrm{T}_{1}=\mathrm{J}_{1}=22\right.$;

$\left.4 \mathrm{~T}_{2}=\mathrm{J}_{2}=18\right)$, while in 1987 only 14 quadrats were sampled in inner forest $\left(\mathrm{T}_{1}=14\right)$ and 6 in edge

5 forest $\left(\mathrm{T}_{2}=6\right)$.

Information about the presence of nesting species was provided by acoustic recognition of

7 singing males according to the following procedure. Listener spent a twenty minutes at each

8 station, listening for birds. This time spent on each quadrat was divided into $K$ equal sessions,

9 here $K=4$, during which detection are recorded. The number of quadrats in region $R_{a}$ in which species $s$ has been detected is denoted by $V_{s}(a)$. Total number of sessions in region $R_{a}$ during

11 which species $s$ has been detected is denoted by $W_{s}(a)$. These data are given in table 1. All records were made following the listening point method (EPS, Spitz 1974, EFP, Blondel, 1975) over a 500-meters sided grid. Length of the side of a quadrat (that is 500 meters) has

14 been chosen so that the listening range (a disk of 150-meter radius) is strictly included within the quadrat. Consequently, from a station performed in a given quadrat, the observer cannot hear songs of (males) conspecifics that would nest in adjacent quadrats; consequently, if the

17 song of a male of a given species $s$ is detected in the quadrat $j$, thus the species $S$ is present in this quadrat. Further details of the protocol can be found in Decamps et al. (1987).

19 The dataset of observations is afterwards denoted by $y$; therefore $y=\left\{y_{s}(a) ; s \in \mathcal{L}, a=1, \ldots, A\right\}$, where $y_{s}(a)$ denotes the observation related to species $s$ in region

$21 R_{a}$. A possible record of $y_{s}(a)$ for a region $R_{a}$ could be $y_{s}(a)=4021003$. Here, $V_{s}(a)=4$, $W_{s}(a)=10$. Finally, the number of detection of species in the sampled quadrat $j$ is denoted by $y_{s j}$ 
$1 \quad$ Underlying processes and missing data structure - To specify the missing data structure

2 inherent in quadrat sampling data, we view the record $y_{s}$ as the result of two processes: one is

3 related to the presence-absence process (in quadrats), and the other is related to the detection

4 process. Such a formalism also allows us to formulate rigorously the biological assumptions

5 made and to introduce, in a natural way, the parameters of biological interest.

$6 \quad$ We denote by $z_{s j}$ the indicator of presence of species $s$ in quadrat $j$; therefore, $z_{s j}=1$ if $7 \quad$ species $s$ is present in quadrat $j$, and 0 otherwise.

Conditioning on $z_{s}=1, X_{s j}$ is the number of times that species $s$ has been detected in

9 quadrat $j$ during the $K$ sessions. It is clear that $x_{s j}=0$ and $y_{s j}=0$ do not have the same

10 meaning. The event $x_{s j}=0$ means that the species $s$ (present in quadrat $j$ ) has not been

11 detect in it; while the event $y_{s j}=0$ resorts two distinct situations. Missing can occur in

12 different circumstances. First, when a species $s$ has not been detected in quadrat $j$ (that is

13 when $y_{s j}=0$ ), it is clear that $z_{s j}$ is missing; the event $y_{s j}=0$ covers in fact two exclusive

14 situations: either species $S$ is present in quadrat $j$ but has not been detected, or it is not 15 present in quadrat $j$ (and cannot have been detected). Formally, one has the equivalence $16\left(y_{s j}=0\right) \Leftrightarrow\left(Z_{\mathrm{sj}}=1\right.$ and $\left.X_{\mathrm{sj}}=0\right)$ or $\left(Z_{s j}=0\right)$. Conversely, when $1 \leq k \leq K$, one has $17\left(y_{s j}=k\right) \Leftrightarrow\left(z_{\mathrm{sj}}=1\right.$ and $\left.x_{\mathrm{sj}}=k\right)$. Second, $z_{s j}$ is also missing, when quadrat $j$ is not a part of 18 the sampled quadrats.

20 Notation - Throughout the paper $p($.$) denotes a probability mass function. The local$ 21 occupancy rate of species $S$ in region $R_{a}$ is denoted by $\gamma_{s a}$; therefore, one has:

$$
\gamma_{s a}=\frac{1}{J_{a}} \sum_{j \in R_{a}} Z_{\mathrm{sj}}
$$


1 We apply the conditional model of Dupuis et al. (2010) to each sub-region $R_{a}$ for estimating

$2 \gamma_{s a}$. Biological assumptions related to the occurence of species in the $J_{a}$ quadrats are

3 supported by the values of $Z_{s j}$, and those related to detection in the $T_{a}$ sampled quadrats by

4 the values of $X_{s j}$.

$6 \quad$ Modeling detectability - We assume that the probability of detecting species $s$ in quadrat $j$

7 does not depend on its detection in the other quadrats. Considering the experimental protocol, 8 size and distance between sampled quadrats, this is a realistic assumption.

$9 \quad$ For any quadrat $j$ of $R_{a}$, we assume that conditionally on $z_{s j}=1, x_{s j}$ follows a $\operatorname{Binomial}\left(K, q_{s a}\right)$. Here $q_{s a}$ represents the probability of detecting species $s$ in quadrat $j$

11 (located in region $R_{a}$ ) during any session (given that it is present in quadrat $j$ ). Detection probability can vary strongly among species, and can also differ depending on the subarea

13 considered. We also can define the parameter $\mu_{s a}=\operatorname{Pr}\left(X_{s j} \geq 1 \mid Z_{s j}=1\right)=1-\left(1-q_{s a}\right)^{K}$ which represents the probability of detecting species $S$ in quadrat $j$ (conditionally on its presence) over the $K$ sessions of a visit. This parameter is commonly the parameter on which prior 16 information is available.

Modeling occupancy-Let $s$ be a species present in the study area $R_{a}$, we set $Z_{s}(a)=\left\{Z_{s j} ; j \in R_{a}\right\}$. Since we adopt a conditional approach, $Z_{s}(a)$ is distinct from the null vector. The p.m.f. (probability mass function) of $Z_{s}(a)$ is:

$$
p\left(z_{s}(a) \mid \varphi_{s a}\right)=\frac{\varphi_{s a}^{N_{s}(a)}\left(1-\varphi_{s a}\right)^{J_{a}-N_{s}(a)}}{1-\left(1-\varphi_{s a}\right)^{J_{a}}}
$$
that species $S$ is present in quadrat $j$ of $R_{a}$, given that it is present in at least one other quadrat 
Occupancy rate modeling for bird species undergoing climatic changes

1 of $R_{a}$. Note that $\varphi_{s a}$ is a conditional occurrence parameter (contrary to what appear in

2 MacKenzie et al., 2006). Also $\gamma_{s a}$ is not a parameter of the model, in contrast to $\varphi_{s a}$; but they

3 are linked, since $E\left[\gamma_{s a} \mid \varphi_{s a}\right]=\varphi_{s a} /\left[1-\left(1-\varphi_{s a}\right)^{J_{a}}\right]$. Due to the conditioning, the random

4 variables $Z_{s j}$ are not independent. However, a certain form of conditional independence

5 between the $Z_{s j}$ 's holds. Let $i, j$ be any two quadrats of $R_{a}, Z_{s i}$ and $Z_{s j}$ are independent, if

6 species $S$ is present in at least one other quadrat of $R_{a}$ (distinct from $i$ and $j$ ).

7 Therefore, from a biological point of view, we assume that the presence of species $s$ in quadrat $i$ is not affected by the presence of that species in quadrat $j$ (given that it is present elsewhere in $R_{a}$ ); this assumption is standard (disregarding the conditioning).

Prior information on species detectability - These data are part of a large study in the Midi-

Pyrénées (i.e. South-West of France), therefore we have access to prior information on the probability of detecting species during the entire visit. Information on this detectability is also available from the literature. It should be noted that, astonishingly, in the literature Bayesian studies using informative priors are not as common as it could be expected. Here, since this information is available and can bring substantial improvements to estimates, we have logically used it in the process of occupancy rate assessing. be define for example as highly detectable or hardly detectable (Blotzheim \& Bauer, 1985, 1988, 1993, 1997). Dupuis \& Joachim (2006) have defined categories of detectability in order to classify bird species depending on this information for 1985. Using information provided by external data, they have found the Beta prior distribution for detection probability $\mu_{s a}$ corresponding to each of these categories. 
Here we use 4 categories: low, intermediate low, intermediate high and high detectability. The mean and $95 \%_{\mathrm{CI}}$ of the prior distributions for each category, respectively, are $0.2[0-$ 0.4], $0.4[0-0.65], 0.6[0.3-0.8]$ and 0.8 [0.65 - 1]. These specific priors for each species are presented in Table 3. We have used the prior means and $\mathrm{CI}_{95 \%}$ intervals on $\mu_{s a}$ to determine coefficients of the corresponding Beta distribution by the use of a binary search algorithm (see MatLab code in appendix 1). Then, these coefficients are used to estimate coefficients of the prior Beta distribution on $q_{s a}$ (the probability that a species is detected during each session of a visit) through the use of classical Monte Carlo methods (see MatLab code in appendix 2). Finally, the prior information on $q_{s a}$ is used to estimate $\gamma_{s a}$.

Prior information on detectability for some species varies between 1985 and 1987 and/or between areas (see Table 3). Modification of detectability classification for some species in 1987 is due to regional specificities or changes in the abundance of individuals. For example, the song thrush is less inclined to sing as the number of conspecifics in the neighborhood decreases. In the case of the whitethroat in the forest interior, no estimation has been done because it is known that this species does not live in this type of environment (therefore, no prior has been specified in table 3).

Likelihood - The parameter of the model is $\theta=\left\{\varphi_{s a}, q_{s a} ; s \in \mathcal{L}, a=1, . ., A\right\}$. The likelihood of $\theta$ based on $y=\left\{y_{s}(a) ; s \in \mathcal{L}, a=1, . ., A\right\}$ is:

$$
L(\theta ; y)=\prod_{s \in \mathcal{L}, a=1, \ldots, A} p\left(y_{s}(a) \mid \varphi_{s a}, q_{s a}\right)
$$

Note that we implicitly assume that species behave independently with respect to occupancy. For any species $s$ such that $y_{s}(a)$ is different from the null vector:

$$
p\left(y_{s}(a) \mid \varphi_{s a}, q_{s a}\right)=\frac{\rho_{s a} \varphi_{s a}{ }^{V_{s}(a)} q_{s a}^{W_{s}(a)}\left[1-q_{s a}\right]^{U_{s}(a)}\left[\left(1-q_{s a}\right)^{K} \varphi_{s a}+1-\varphi_{s a}\right]^{T_{a}-V_{s}(a)}}{1-\left(1-\varphi_{s a}\right)^{J_{a}}}
$$


$1 \quad$ where $U_{s}(a)=K V_{s}(a)-W_{s}(a)$, and $\rho_{s a}=\prod_{j \in R_{a}}\left(\begin{array}{l}K \\ y_{s j}\end{array}\right)$; moreover, if $y_{s}(a)$ is a null vector, we

2 have:

$$
p\left(y_{s}(a) \mid \varphi_{s a}, q_{s a}\right)=\frac{\left(\left(1-q_{s a}\right)^{K} \varphi_{s a}+1-\varphi_{s a}\right)^{T_{a}}-\left(1-\varphi_{s a}\right)^{J_{a}}}{1-\left(1-\varphi_{s a}\right)^{J_{a}}}
$$

Computational details are available from the authors on request. The formulae (1.1) and (1.2) allow computation of the probability (in function of $J_{a}, T_{a}, K, \varphi_{s a}$ and $q_{s a}$ ) that a species $s$ present in $R_{a}$ has not been detected (or rarely detected). This occurs with relatively high probability when species $s$ is spatially rare and/or hard to detect (Dupuis et al., 2010).

Estimating the occupancy rate - We use Monte Carlo Markov Chain methods (MCMC) in order to obtain the bayesian estimations of $\gamma_{s a}$. Here, we are especialy interested is the estimation of the occupancy rate but in some cases it could be required to also estimate the parameters $q_{s a}$ and $\varphi_{s a}$. The MCMC algorithm, taking advantage of the missing data structure, is implemented on $\left(\theta, Z_{m}\right)$ where $Z_{m}=\left\{Z_{s}^{m i s}(a) ; s \in \mathcal{L}, a=1, . ., A\right\}$ and $Z_{s}^{m i s}(a)$ is the set of the missing $Z_{s j}$ 's related to $s$ (where $j$ is in $R_{a}$ ). The bayesian estimate of $\gamma_{s a}$ is easily obtained by applying the ergodic theorem (details are omitted). For further details, refer to Dupuis et al. (2010). The MatLab code for estimating $\gamma_{s a}, \varphi_{s a}$ and $q_{s a}$ is provided in Appendix 3.

We also compare differences between estimates obtained under both MacKenzie et al., (2006) unconditional and Dupuis et al. (2010) conditional approaches in the case of not detected species that are known to be present and easily detectable. This comparison is done with non informative and informative priors on the detection probability. 
Occupancy rate modeling for bird species undergoing climatic changes

1 Globally, occupancy rates variations between 1985 and 1987 do not seem to be mainly

2 directed by the migratory status (Tab. 4). For example, while some sedentary species'

3 occupancy rates decreases (e.g. the short-toed treecreeper), others have increased (e.g. the

4 Eurasian nuthatch). The same result exists for migrating species and partial migrants (e.g.

5 mistle thrush occupancy rates increased contrary to the song thrush).

6

Overall, occupancy rates in interior and edge forests presented the same type of changes (i.e. increase or decrease), but the extent of these variations can differ between these two subareas. For example, while the song thrush and the nightingale greatly retreat between 1985 and 1987 in the edge forest, this variation is less important in the inner forest. On the other side, increase in mistle thrush population was more important in the inner forest than in the edge forest, apparently revealing a protecting role of the inner forest.

In the end, variations of occupancy rates seem to be mainly driven by biogeographical origins with an occupancy rate increase of European and continental species (e.g. mistle thrush, Eurasian nuthatch, European robin) and a decrease of Mediterranean and Atlantic species (e.g. nightingale, song thrush).

We observe that the bayesian non informative estimates of the occupancy rates are precise when the number of detections is high. Moreover, in 1987 and in edge, most of species have been few detected (except the common blackbird, the chiffchaff, and the mistle trush), and, not surprisingly, we observe that most of non informative estimates are imprecise.

We also observe that taking into account the prior information available on detectability significantly improves the precision of estimates when the target species has been very few detected $\left(W_{s}(a)=1\right)$ or has not been detected $\left(W_{s}(a)=0\right)$ : the green woodpecker, the nightingale 
Occupancy rate modeling for bird species undergoing climatic changes

1 and the whitethroat are concerned by this remark (tab. 4 and 5). In Dupuis et al (2010), this

2 observation has already been mentioned, and indicated that this improvement is particularly

3 significant when the target is highly detectable.

Finally, we observe that taking into account the prior can make decrease the precision of the bayesian estimate. For the mistle trush (in 1987 and in inner forest), the range of the $95 \%$ posterior credible interval is 0.37 in non informative situation, and 0.46 in informative situation. This unusual phenomenon typically occurs when the two following conditions are fullfilled: the weights of the data and the prior are similar, and the (informative) prior mean of the parameter of interest and its (non informative) posterior mean are very different, which indicates a 'conflict' between the prior and the data. In our case, the prior variance of $q_{s a}$ in informative situation (namely $0.075^{2}$ ) is effectively relatively close to the posterior variance of $q_{s a}$ in non informative situation (namely $0.084^{2}$ ), while the (informative) prior mean of $q_{s a}$ (namely 0.21 ) is effectively very far from the non informative posterior mean of $q_{s a}$ (namely $0.66)$.

Use of priors here can be essential to obtain a better estimation of occupancy rates. For example, raw data in edge forest are identical for the whitethroat (1985) and for the green woodpecker (1987). With $V_{s}(a)=2$ and $W_{s}(a)=2$ for these 4 species, we would have failed to detect variation in occupancy rate without prior information (e.g. for the whitethroat), or we could have underestimated the extent of the species occupancy rate variation (e.g. for the green woodpecker). We can highlight the importance of including prior information on detectability when available in the case of low detection data and easily detectable species.

For a species not detected by the quadrat sampling, but for which it is known that it was in fact present in the region of study $\mathrm{R}_{\mathrm{a}}$ (e.g. the Green Woodpecker in 1985 or the Nightingale in 1987 in edge forest), tables $6 \mathrm{a}$ and $6 \mathrm{~b}$ show that ignoring such an additional information (by using the unconditional MacKenzie et al., 2006, approach) will underestimate $\gamma_{s a .}$ In non 
Occupancy rate modeling for bird species undergoing climatic changes

1 informative situation, distances between both estimates are very important when the region of

2 study has been entirely sampled ( $\mathcal{=}=18$ ) (tab. 6a), and less important (though not negligible)

3 in the opposite case $(J=18, T=6)$ (tab. $6 \mathrm{~b})$. In informative situation, distances in absolute

4 values are definitely less important (though not negligible), regardless the region of study is

5 totally or partially sampled. Nevertheless, we note that when $\mathcal{E}=18$ the ratio between both

6 estimates is particularly high (namely $>3.5$ ). To be complete, let us add that when the target

7 species has been well detected estimates obtained under conditional and unconditional 8 approaches are quite similar.

9

10

11 Discussion

Globally, occupancy rates variations between 1985 and 1987 do not seem to be mainly directed by the migratory status and no important differences between interior forest and edge forest has been shown. The main factor responsible for species' response to climate changes appeared to be their biogeographical region of origin.

Migratory status - Contrary to what we expected, the species migratory status did not seem to be an important cause of differences in changes of occupancy rates under climate changes. Evolution of occupancy rates as a response to climate changes could have been affected because of direct effects on bird species of these changes, or secondary consequences. For example, decrease may be due to the direct impact of rigorous winters on populations (especially for sedentary species) or indirect impacts such as a decrease in available resources (particularly for migratory species that should not be affected by the direct consequences of cold in the region). An increase of occupancy rates or a less important impact of the specific regional climatic events might be expected because other species might be negatively 
Occupancy rate modeling for bird species undergoing climatic changes

1 impacted by cold winters and therefore leave unused resources and part of ecological niche.

2 Variation in population is the result of trades-offs between these negative and indirect positive

3 consequences and the influence of other external factors (e.g. a population already in a

4 decrease phase).

5 The impact of climatic extremes on bird densities is well-known (Wiens, 1981,

6 Grzybowsky 1983, Balda et al., 1983 ; Hejl \& Beedy, 1986). According to these authors,

7 rigorous winters affect sedentary but not migratory bird species. In our study area,

8 Palearctic and Turkestano-european faunistic type species expanded, while European,

9 Turkestano-mediterranean and Mediterranean sedentary species experience population

10 reductions or extinction. This signifies a continentalization of the local avifauna. However,

11 not all of the sedentary birds were negatively affected by cold winters. Woodpeckers,

12 Eurasian Nuthatch and tits population increased. Fauna continentalization can also be seen

with migrants. Whitethroat, Tree Pipit, Spotted Flycatcher, but also Yellow Wagtail, Redbacked Shrike and Garden Warbler have increasing occurrence frequencies.

The absence of clear impact of the migratory status can be due to the specific characteristics of some of the species' local populations. For example, the Chiffchaff, which has an important over-wintering population in Midi-Pyrenees, is found in winter near to stagnant and running waters in the plain, where birds are sedentary. It is therefore strongly affected by rigorous winters, leading to a drop in numbers in riparian forest, observed between 1985 and 1987 (Lauga \& Joachim, 1992). However, local populations, which are 21 mainly migratory outside of riparian forests, are not greatly affected (Affre, 1975 $b$; Joachim et al., 1997). Another example implies the European Robin. It was a common bird in this region before the cold January of 1985. Rarer in 1985 spring, it almost disappeared from the study area by spring 1987. It was only present in the largest terrace forest where its frequency was greatly reduced $(\mathrm{F}=30 \%$ instead of $80 \%$ in 1985$)$. This local extinction happened in 
Occupancy rate modeling for bird species undergoing climatic changes

1 plains and hills of the piemont Garonne. However, in mountainous areas such as Haute-

2 Garonne Pyrenees and Ariège, no significant frequency variation occurred between 1985 and

3 1987: $\mathrm{F}=100 \%$ for Cagire beech groves (Haute-Garonne, $1000 \mathrm{~m}$ ) and beech and birch groves

4 in the Beille plateau (Ariège, 800-1400m) for both years (Joachim et al., 1997). Therefore, it

5 can be hypothesized that the European Robin from the Garonne plains was sedentary and did

6 not survive the rigorous winters while the one from Central Pyrenees are migratory and

7 avoided these winters. Génard \& Lescourtet (1985) found insular type adaptative characters in

8 European Robin of the Pyrenees. However, this species general range skirts Mediterranean

9 areas and shows no interruption between Pyrenees and the rest of France. Therefore, the

10 authors could not explain this phenomenon. Recent events suggest a distinction between East

11 and Central Pyrenees populations and more northern populations. First, during cold winters,

12 the Garonne population disappears and there is a real separation between areas. Second, during mild winters, a sedentary Garonne population of European Robin develops but because it is sedentary, it stays isolated from migratory Pyrenees' European Robins which have then developed specific insular peninsular characteristics.

Interior vs. edge forest - We have not detected significant differences between interior and edge forest, and globally species occupancy rates seemed to vary the same way in these two sub-area. No changes of habitat preferences has been detected, but response to climate changes might be less important in some cases in the interior forest than in the edge forest

21 indicating that actually, the interior forest might have provided a better protection. The extent 22 of this phenomenon may even be more important that what we could see here. In fact, because of the poor sampling rate in the edge forest, the credible intervals of estimates are large leading to a possible underestimation of the protection role played by the inner forest. It is 
1 interesting to note that without the use of prior information, the detection of this effect would

2 have been compromised.

3 On a larger scale, detected variations in frequency are generally associated to colonization

4 or retreat from areas that do not correspond to preferred habitat (defined by sampling from 5 1985; Joachim, 1986). Largely wide-spread in woods located in this area, the Chiffchaff has 6 partially retreated from riparian forests while wren populations decreased in terraces. Birds 7 that are mainly forest birds have colonized small groves (e.g. Mistle Thrush, Lesser Spotted 8 Woodpecker), and open-field birds have penetrated into forest edges (e.g. Tree Pipit, 9 Whitethroat). These clues suggest that bird species with continental affinities, even if 10 progressing for various reasons, have difficulties in finding their optimal habitat. The local 11 frequency increase with occupation of unusual environments might reflect healthy 12 neighboring continental populations (e.g. in northern France, the Massif Central, or the Pyrenees) with individuals that would settle in environments marginal to our region. Such phenomena have been demonstrated by Askins \& Philbrick (1987), and Askins et al. (1987) for forest fauna in Connecticut (USA), by Van Dorp \& Opdam (1987) in Dutch groves, and by Helle \& Järvinen (1986) in northern Finland.

In open-fields of near the study area, ornithologists have pointed out the disappearance of some species (Cisticola juncidis, Indo-african faunistic type, Sylvia undata, Mediterranean faunistic type), but no disappearance has been noticed in woody areas. Cettia cetti has undergone a drastic regression in riparian forests without disappearing, and so has Erithacus

21 rubecula in all forests. Globally, species from forest areas seems to cope better with climatic 22 variations (even if affected) than sedentary open-field species. Some forest species have even profited of new climatic conditions. 
Occupancy rate modeling for bird species undergoing climatic changes

1 Role of the species' biogeographical origins - Continentalization of the regional forest fauna

2 has not been yet reflected by loss or gain of species, but instead by population reduction or

3 expansion by locally common species. However, some species have been more affected and

4 show a general reduction (or even extinction) or global colonization in the studied area. Some 5 extant monitoring programs such as the European Bird Census Council

6 (http://www.ebcc.info/) are interested in the expansion or regression of occupied areas of

7 several species, but no particular attention is drawn to the biogeographical origins of species,

8 which, as shown here, can be crucial.

In a broader context, during the 1970 's, a different situation occurred with the settlement or expansion of Mediterranean species (e.g. Dartford Warbler, Subalpine Warbler, Woodchat Shrike), Turkestano-Mediterranean species (e.g. : Cetti's Warbler, Bee-eater) or Indo-African species (Zitting Cisticola) in our study area during a succession of mild winters (Affre 1975a and $b$, Yeatman 1974). This expansion often extended to the French Atlantic coast which provided a mild winter climate (Yeatman, 1976). Highly contrasting seasons from 1985, 1986 and 1987 have been correlated with regression and even local extinction of sedentary populations to the benefit of these colonizing species, leaving small populations on the Atlantic coast (e.g. Warblers). Depending on annual climatic variations, the Val de Garonne area is alternatively colonized by Mediterranean thermophilic species using early stages of plant successions, or continental species (especially forest species) uncomfortable in isolated wood patches present in the agricultural plains (Blondel, 1984). These temporary 21 colonizations still permit the exchange of individuals between populations that are 22 intermittently isolated from each other (e.g. populations from the Pyrenees' continental fauna and mid-Europe reservoir, and Mediterranean populations from the Atlantic coast and

24 Mediterranean reservoir). European partial migratory species with a sedentary edge area that 25 encompass the South-West of France hardly succeed to sustaining populations. 
Occupancy rate modeling for bird species undergoing climatic changes

1 Various biogeographical influences acting on this region, usually thought to be an 2 enriching factor to natural environment, here, are paradoxically related to a noticeable 3 faunistic deficit (Balent et al., 1988). Climatic variations and advanced deforestation only

4 allow commonly wide-spread species and pioneer species. Riparian Garonne forest seems to 5 be important, because regardless of climatic conditions, it contains a fauna of diverse 6 biogeographical regions, such as the Turkestano-Mediterranean Cetti's Warbler, the European 7 Garden Warbler (Affre, 1980) and the palearctic Marsh Tit (Joachim, 1987). Avifauna responses to climatic variations are slower here than in the open-fields of neighboring agricultural plains. While the Garonne riparian forest, with a small area, can not be a local fauna local reservoir and populations therein are not as unchanging as in large forest areas (Glowacinski, 1981). It constitutes a moderating element in Garonne landscape because of its slow response to climatic variations,. It also provides a more or less hospitable link between remote patches of biogeographically different faunas and their source areas.

Taking into account some prior on the detectability of the target species can significantly improve the estimation of its occupancy rates when it has been very few detected (or not detected) and is known to be easily detectable (as already pointed out by Dupuis et al., 2010). As a matter of fact, ignoring such an available prior may have led to different conclusions such as detection of a variation in occupancy rate while not true (e.g. Green Woodpecker or

21 Whitethroat in edge forest), a wrong estimation of the impact of rigorous winters (e.g. 22 Nightingale or European Robin in edge forest), or worse, it would have failed to detect a diminution of the occupancy (e.g. Nightingale in the inner forest). Moreover, in our dataset, we have undetected species which were known to be present in the study area; we have thus adopted the conditional approach of Dupuis et al. (2010) for estimating their occupancy rates. 
Occupancy rate modeling for bird species undergoing climatic changes

1 As shown in the comparison between unconditional and conditional approaches, not

2 accounting for the known presence of an undetected species can lead to significant 3 underestimation of its occupancy rate.

4 
Occupancy rate modeling for bird species undergoing climatic changes

\section{Appendices}

2

3

4

5

6

7

8

9

10

11

12

13

14

15

16

17

18

19

20

21

22

23

39

40

41

42

43

Appendix 1. MatLab code for the binary search algorithm to determine the coefficients of the Beta distribution placed on detection probability over the whole visit $\mu_{s a}$ from a prior mean and $95 \%$ credible interval. Output: Beta distribution parameters a and $b$.

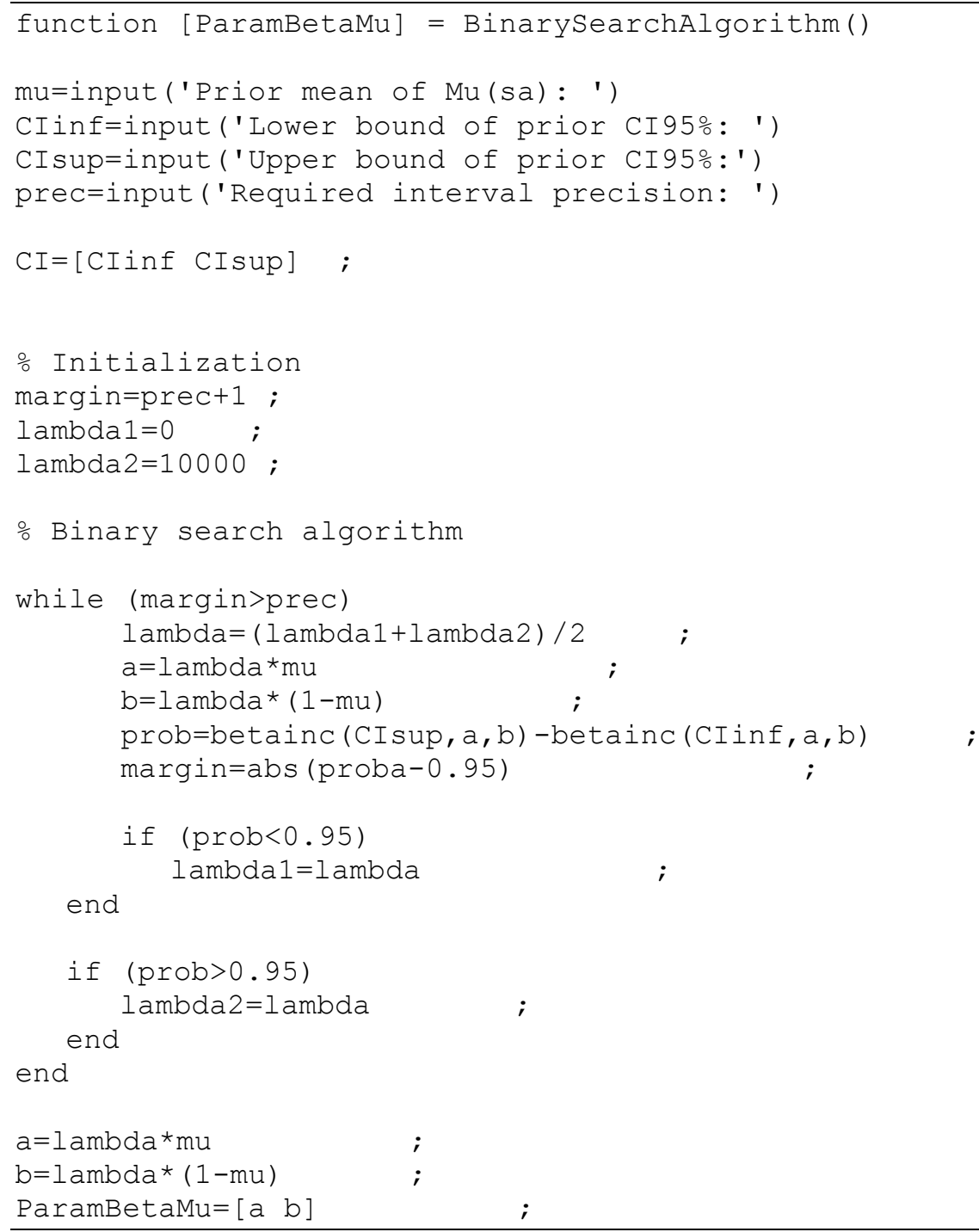


Occupancy rate modeling for bird species undergoing climatic changes

Appendix 2. MatLab code to obtain the Beta distribution parameters on $q_{s a}$ (detection probability during each session of a visit) from the Beta distribution on $\mu_{s a}$. Input: Beta distribution parameters on $\mu_{\text {sa }}$ provided by function BinarySearchAlgorithm(). Output: Beta distribution parameters for $q_{s a}$.

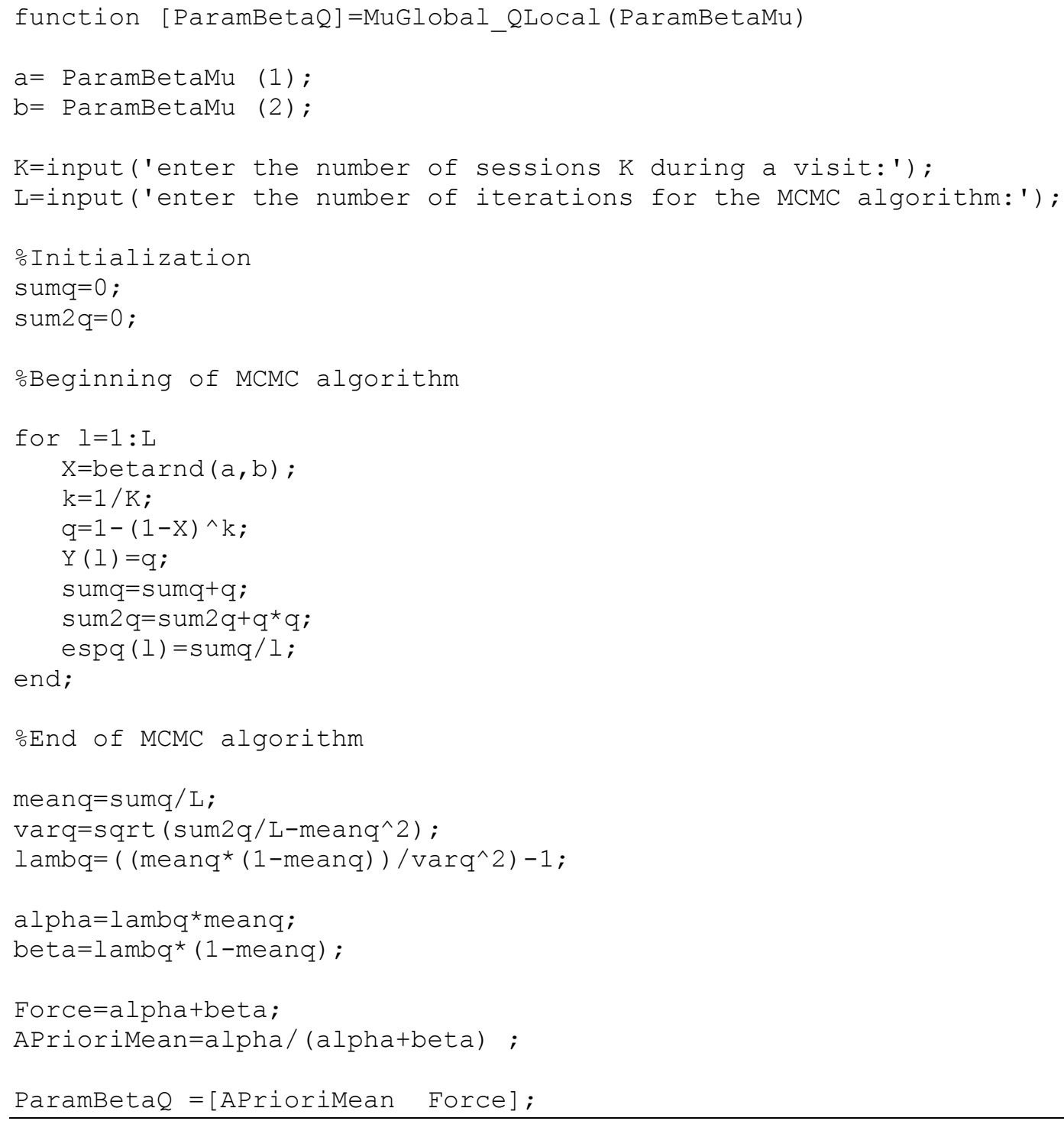


Occupancy rate modeling for bird species undergoing climatic changes

1 Appendix 3. MatLab code for estimating $\gamma_{s a}$ (and $\varphi_{s a}$ and $q_{s a}$ if required) using the Data 2 Augmentation scheme: $\varphi_{s a}$ is updated via a Hasting-Metropolis step, $q_{s a}$ and missing data via 3 a Gibbs step. Input: Total number Vobs of quadrats where the species of interest has been 4 detected, total number $W$ of detection of targeted species, total number $J$ of quadrats in region $R_{a}$, number $T$ of sampled quadrats, number $K$ of sessions per visit, number $L$ of iterations for the MCMC algorithm. Output: Estimates of posterior mean and 95\% credible interval for occupancy rate $\gamma_{\text {sa. }}$.

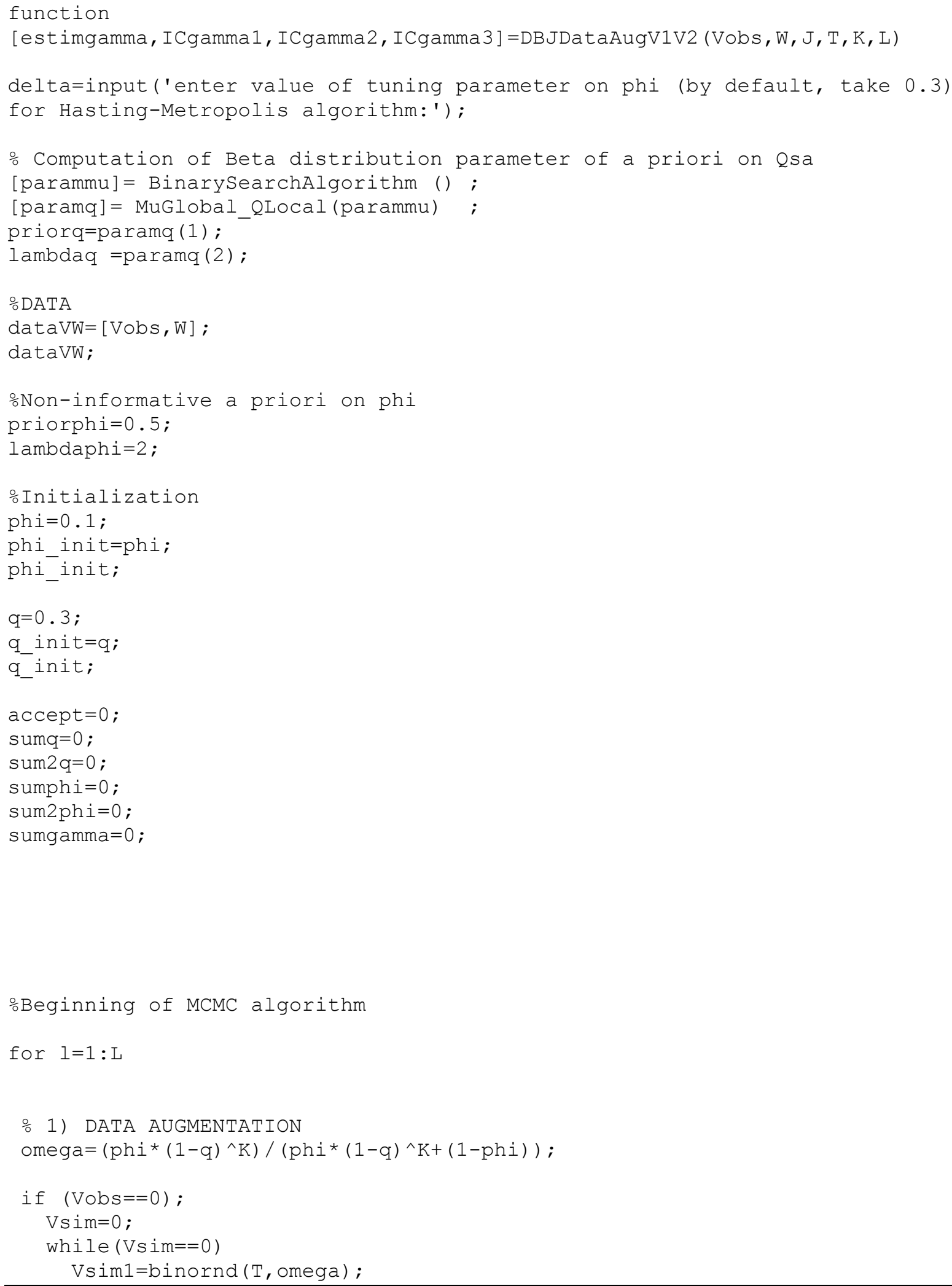




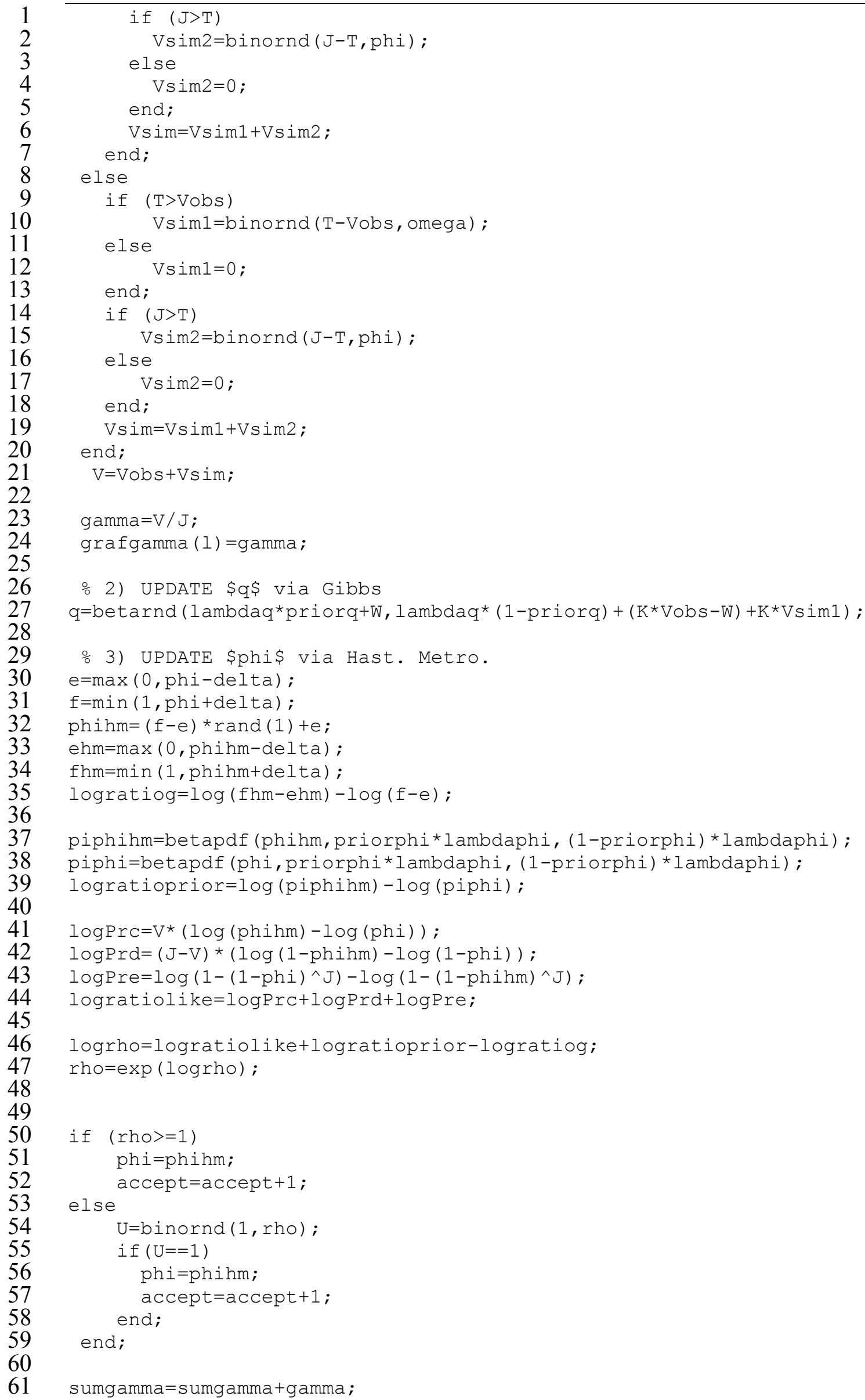




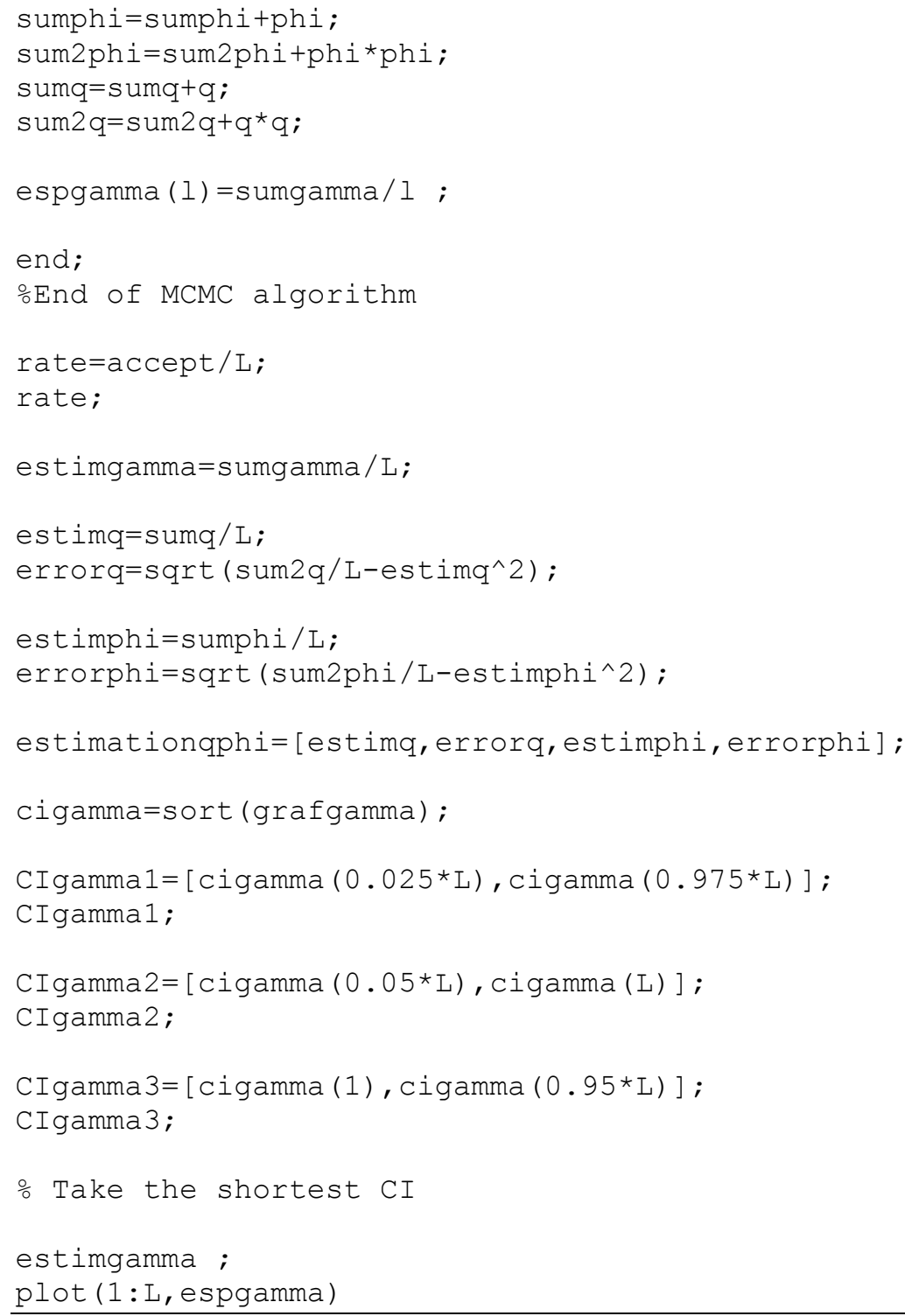

39 


\section{Acknowledgements}

\section{References} helpful comments.

Authors are grateful to Michael C. Runge, Roger Pradel and Kyle G. Dexter for their

Ackerly D.D., 2003. Community assembly, niche conservatism, and adaptative evolution in changing environments. International Journal of Plant Sciences. 164(Suppl.):165-184.

Affre G., 1975a. Dénombrement et distribution géographique des fauvettes du genre Sylvia dans une région du midi de la France. II. Résultats. Alauda. 43: 229-262.

Affre G., 1975b. Estimation de l'évolution quantitative des populations aviennes dans une région du midi de la France au cours de la dernière décennie (1963-1972). L'oiseau et la R.F.O. 45: 165-187.

Affre G., 1980. Distribution altitudinale des oiseaux dans l'Est des Pyrénées françaises. L'Oiseau et la R.F.0. 50: 1-22.

Ainley D.G., Ballard G., Emslie S.D., Fraser W.R., Wilson P.R. \& Woehler E.J., 2003. Adelie penguins and environmental change. Science. 300: 429-430.

Askins R. A. \& Philbrick M. J., 1987. Effect of changes in regional forest abundance on the decline and recovery of a forest bird community. The Wilson bulletin. 99: 7-21.

Askins R. A., Philbrick M. J. \& Sugeno D. S., 1987. Relationship between the regional abundance of forest and the composition of forest bird communities. Biological conservation. 39: 129-152.

Balda R. P., Gaud W. S. \& Brawn J. D., 1983. Predictive models for snag nesting birds. 216-222. In J. W. Davis, G. A. Goodwin, and R. A. Ockenfels, Snag Habitat Management : Proceedings of the Symposium. U.S. Department of Agriculture, Forest Service, General 
Occupancy rate modeling for bird species undergoing climatic changes

1 Technical Report RM-99. Rocky Mountain Forest and Range Experiment Station, Fort 2 Collins, $\mathrm{CO}$.

3 Balent G., Génard M. \& Lescouret F., 1988. Analyse des patrons de répartition des oiseaux

4 nicheurs en Midi-Pyrénées. Acta oecologica. Oecologia generalis. 9: 247-263.

5 Blondel J., 1975. L'analyse des peuplements d'oiseaux, éléments d'un diagnostic écologique

6 1; La méthode des échantillonnages fréquentiels progressifs (E.F.P.). Revue d'Ecologie. $7 \quad 29: 533-589$.

Blondel J., 1984. Avifaunes méditerranéennes, histoire des peuplements. Aves. 21: 209-226.

Blotzheim U.N. \& Bauer K.M., 1985, 1988, 1993, 1997. Handbuch der Vogel Mitteleuropas. Aula-Verlag, Wiesbaden.

Colombo A.E., Etkin D. \& Karney B.W., 1999. Climate Variability and the Frequency of Extreme Temperature Events for Nine Sites across Canada Implications for Power Usage. American Meteorological Society. 12: 2490-2502.

Coope G.R., 1994. The response of insect faunas to glacial-interglacial climatic fluctuations. Philosophical Transactions: Biological Sciences. 344: 19-26.

Croxall J.P., Trathan P.N. \& Murphy E.J., 2002. Environmental change and Antarctic seabird populations. Science. 297: 1510-1514.

Davis M.B. \& Zabinski C., 1992. Changes in geographical range resulting from greenhousewarming: effects on biodiversity in forests. 297-308. In: Global Warming and Biological Diversity, ed. TEL Peters, R Lovejoy. New Haven, CT: Yale Univ. Press.

Décamps H., Joachim J., \& Lauga J., 1987. The importance for birds of the riparian woodlands within the alluvial corridor of the river Garonne, SW France. Regulated rivers : research and management. 1: 301-316. Ecology. 47: 267-275. 
Occupancy rate modeling for bird species undergoing climatic changes

1 Dupuis J., Bled F. \& Joachim J., 2010. Estimating the occupancy rate of spatially rare or

2 hard to detect species: a conditional approach. Biometrics. (in press)

3 Dupuis J. \& Joachim J., 2006. Bayesian estimation of species richness from quadrat 4 sampling data in the presence of prior information. Biometrics $62,706-712$.

5 Génard M. \& Lescouret F., 1985. Caractères insulaires de l'avifaune forestière des Alpes du 6 sud et des Pyrénées-Orientales. Acta oecologica. Oecologia generalis. 6: 209-221.

$7 \quad$ Glowacinski Z., 1981. Stability in bird communities during the secondary succession of a forest ecosystem. Ekologia Polska. 29: 73-95.

9 Grabherr G., Gottfried M. \& Pauli H., 1994. Climate effects on mountain plants. Nature. 369: 448.

Grzybowsky J. A., 1983. Patterns of space use in grassland bird communities in winter. The Wilson Bulletin. 95: 591-602.

Hanski I., 1997. Metapopulation dynamics: from concepts and observations to predictive models. 69-91. In: Metapopulation biology. Eds.: I. Hanski \& M. E. Gilpin. San Diego: Academic Press.

Hej| S. J. \& Beedy E. C., 1986. Weather induced variation in the abundance of birds. 241244. In: Verner J., Morisson M. L. and Ralph C. J. Wildlife 2000, Modeling Habitat Relationships of Terrestrial Vertebrates. The University of Wisconsin Press, Madison, Wisconsin.

Helle P. \& Järvinen 0., 1986. Population trends of north finnish land birds in relation to their habitat selection and changes in forest structure. Ö̈kos. 46: 107-115.

Hill J.K., Thomas C.D., Fox R., Telfer M.G. \& Willis S.G., 2002. Responses of butterflies to twentieth century climate warming: implications for future ranges. Proceedings of the Royal Society B. 269: 2163-2171. 
Occupancy rate modeling for bird species undergoing climatic changes

1 Hoegh-Guldberg 0., 1999. Climate change, coral bleaching and the future of the world's

2 coral reefs. Marine \& Freshwater Research. 50: 839-866.

3 Huntley B., 1991. How plants respond to climate change: migration rates, individualism and

4 the consequences for the plant communities. Annals of Botany. 67: 15-22.

5 Joachim J. \& Lauga J., 1992. Influence des hasards climatiques sur les communautés de 6 passereaux nicheurs dans les boisements du couloir alluvial garonnais. Le Pistrac. 14: 1-17. $7 \quad$ Muséum Toulouse.

Joachim J., 1986. Influence du morcellement forestier sur les peuplements d'oiseaux nicheurs dans le couloir alluvial garonnais. Ph.D. thesis in Ecology. Université Toulouse III. Joachim J., 1987. La Mésange nonnette Parus palustris dans les ripisilves garonnaises. Alauda. 55: 112-115.

Joachim J., Bousquet J.F. \& Fauré C., 1997. Atlas des oiseaux nicheurs de MidiPyrénées. AROMP Ed. Museum d'Histoire Naturelle, Toulouse. 262p.

Kendall W. L., 2001. Using models to facilitate complex decisions. 147-170 In: Modeling in natural resource management. Eds: T. M. Shenk \& A. B. Franklin. Island Press, 16 Washington, D.C.

Krebs C., 1978. Ecology: The Experimental Analysis of Distribution and Abundance. Harper and Row Publishers, Inc., New York, New York, USA.

Lande R., 1988. Demographic models of the northern spotted owl (Strix occidentalis caurina). Oecologia. 75: 601-607.

21 Lauga J. \& Joachim J., 1992. Modelling the effects of forest fragmentation on certain species of forest-breeding birds. Landscape Ecology. 6(3): 183-193.

Levins R., 1969. Some demographic and genetic consequences of environmental heterogeneity for biological control. Bulletin of the Entomological Society of America. 15: 237-240. 
Occupancy rate modeling for bird species undergoing climatic changes

1 Levins R., 1970. Extinction. 75-107 In: Some mathematical problems in biology. Ed: M.

2 Gerstenhaber. Providence, RI: American Mathematical Society.

3 MacKenzie D.I., Nichols J.D., Lachman G.B., Droege S., Royle A.J. \& Langtimm A.C.,

4 2002. Estimating site occupancy rates when detection probabilities are less than one.

$5 \quad$ Ecology. 83: 2248-2255.

6 MacKenzie D.I., Nichols J.D., Royle J.A., Pollock K.H., Bailey L.L. \& Hines J.E., 2006.

7 Occupancy Estimation and Modeling. Academic Press. San Diego, California, USA. 324p.

8 Malcom J.R., Liu C., Neilson R., Hansen L. \& Hannah L., 2006. Global Warming and

9 Extinctions of Endemic Species from Biodiversity Hotspots. Conservation Biology. 20(2):

$10 \quad 538-548$.

11 Mikkola K., 1997. Population trends of Finnish Lepidoptera during 1961-1996. 12 Entomologica Fennica. 3: 121-143.

13 Nichols J.D., 2004. Evolution of quantitative methods for the study and management of avian 14 populations: on the importance of individual contributions. Animal Biodiversity and Conservation. 27(1): 3-19.

Parmesan C., 2006. Ecological and Evolutionary Responses to Recent Climate Change. Annual Review of Ecology, Evolution, and Systematics. 37: 637-69.

18 Parmesan C., Ryrholm N., Stefanescu C., Hill J.K. \& Thomas C.D., 1999. Poleward shifts in geographical ranges of butterfly species associated with regional warming. Nature. 399: $579-583$.

21 Pauli H., Gottfried M. \& Grabherr G., 1996. Effects of climate change on mountain ecosystems: upward shifting of mountain plants. World Resource Review. 8: 382-390.

23 Pounds J.A., Fogden M.P.L. \& Campbell J.H., 1999. Biological response to climate change on a tropical mountain. Nature. 398: 611-615. 
Occupancy rate modeling for bird species undergoing climatic changes

1 Pounds J.A., Fogden M.P.L. \& Masters K.L., 2005. Case study: responses of natural 2 communities to climate change in a highland forest. 70-74. In: Climate change and

3 biodiversity. Eds: T.E. Lovejoy \& L. Hannah. Yale University Press, London.

4 Spitz F., 1974. Facteurs de répartition de l'avifaune en forêt de montagne. In: Écologie 5 forestière: la forêt: son climat, son sol, ses arbres, sa faune: ouvrage collectif. $E d$ : Pearson $6 \quad$ P. Gauthier-Villars, Paris. 382 p.

7 Stirling I., Lunn N.J. \& Iacozza J., 1999. Long-term trends in the population ecology of 8 polar bears in western Hudson Bay in relation to climatic change. Arctic. 52: 294-306.

9 Thomas C.D. \& Lennon J.J., 1999. Birds extend their ranges northwards. Nature. 399: 213.

10 van Dorp D. \& Opdam P.F.M., 1987. Effects of patch size, isolation and regional 11 abundance on forest bird communities. Landscape Ecology. 1: 59-73.

12 Wiens J.A., 1981. Single-sample surveys of communities : are the revealed patterns real? $13 \quad$ American naturalist. 117: 90-98.

14 Wilkinson C.R., ed., 2000. Global Coral Reef Monitoring Network: Status of Coral Reefs of 15 the World in 2000. Townsville, Qld: Aust. Inst. Mar. Sci

16 Williams B.K., Nichols J.D. \& Conroy M.J., 2002. Analysis and Management of Animal 17 Populations. San Diego, California, Academic Press.

18 Yeatman L., 1974. Les rapports entre des caractères climatiques et botaniques et la 19 distribution des oiseaux méditerranéens en France. L'oiseau et la R. F. 0. 44: 324-339.

20 Yeatman L., 1976. Atlas des oiseaux nicheurs de France. Société Ornithologique de France, $21 \quad$ Paris. 
Occupancy rate modeling for bird species undergoing climatic changes

\section{Tables and Figures}

2

3 Figure 1. European map of biogeographical region and location of Montech Forest. (using

4 data provided by the European Environmental Agency: www.eea.eu.int). (Black point: Montech Forest, Cross hatch: Alpine, Diagonal simple hatch: Atlantic, Ordered stipple: Continental, Horizontal simple hatch: Mediterranean).

7

8 Figure 2. Mean monthly temperatures in 1985, 1986 and 1987 (Spotted line: 1985, Hachted line: 1986, solid line: 1987) compared to $1970-1984$ period (maximum and minimum values from this 14 year period bounded in gray).. (from Joachim \& Lauga, 1992) 
Occupancy rate modeling for bird species undergoing climatic changes

Figure 1.

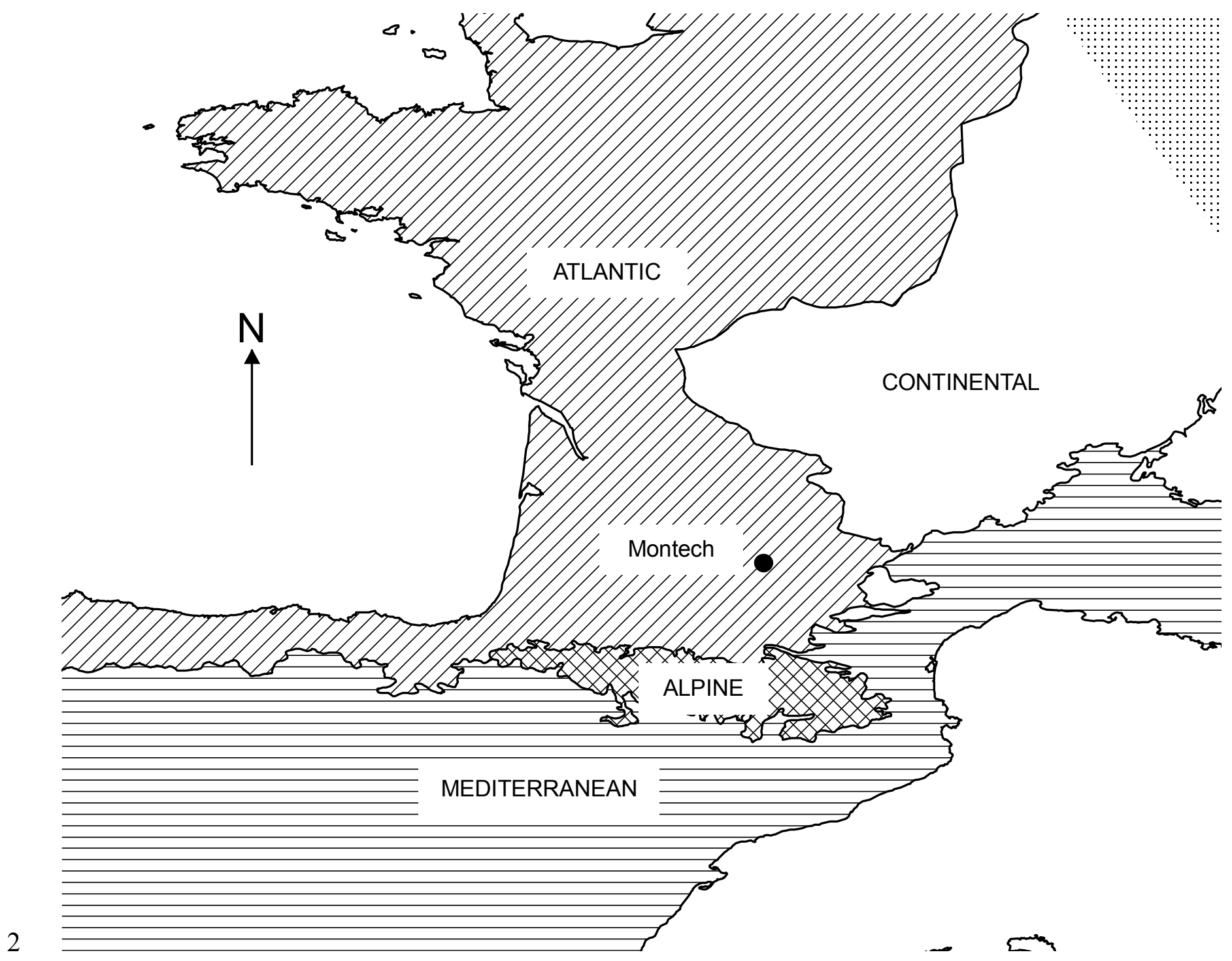


Figure 2.

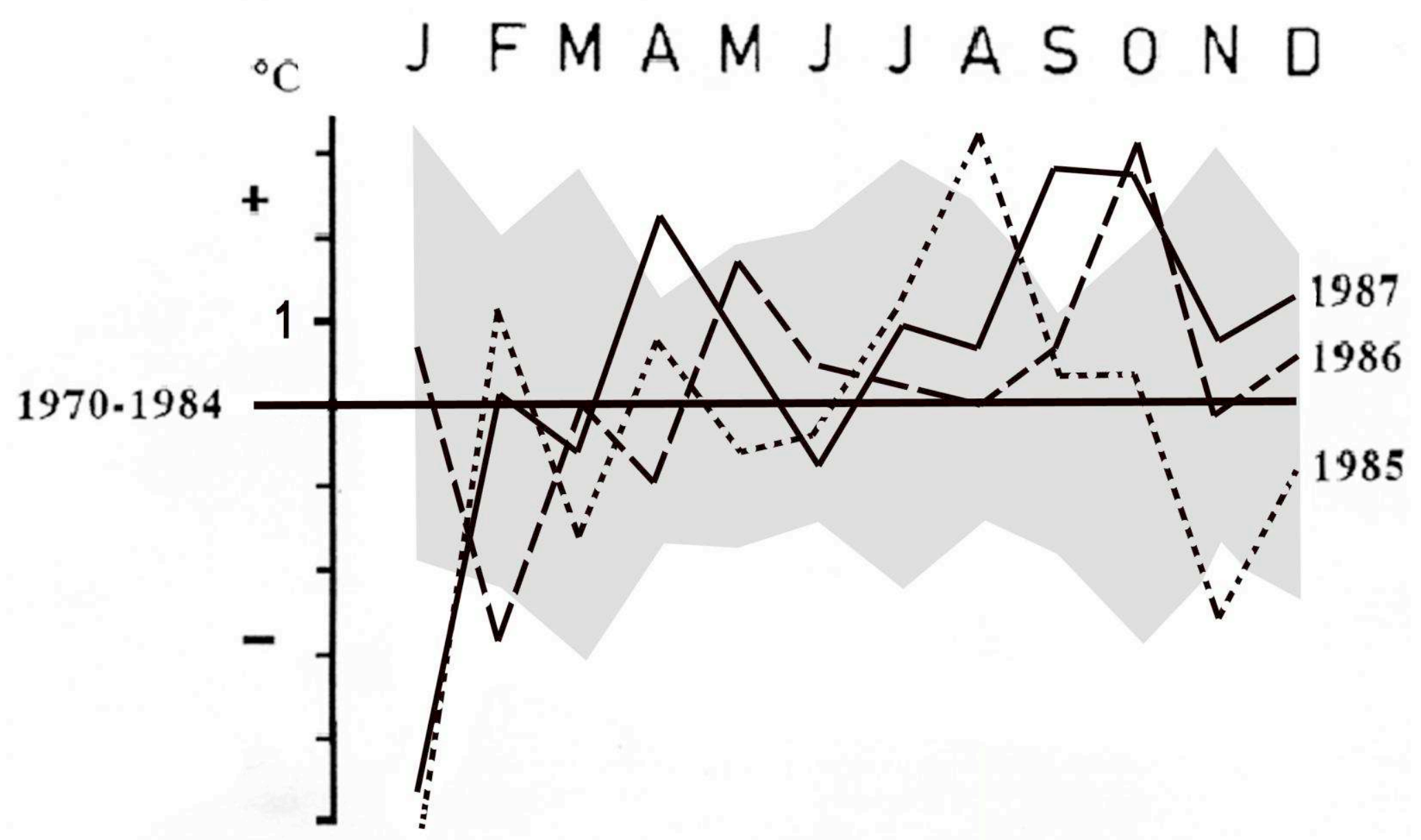


Occupancy rate modeling for bird species undergoing climatic changes

Table 1.

Table 1. Data $\left(V_{s}(a) ; W_{s}(a)\right)$ for 1985 and 1987 in Montech forest.

\begin{tabular}{|c|c|c|c|c|c|}
\hline \multirow{2}{*}{ Species } & & \multicolumn{2}{|c|}{ Inner forest } & \multicolumn{2}{|c|}{ Edge forest } \\
\hline & & 1985 & 1987 & 1985 & 1987 \\
\hline Song Thrush & Turdus philomelos & $(20 ; 53)$ & $(10 ; 20)$ & $(16 ; 43)$ & $(1 ; 2)$ \\
\hline Common Blackbird & Turdus merula & $(17 ; 32)$ & $(12 ; 25)$ & $(14 ; 35)$ & $(4 ; 6)$ \\
\hline Whitethroat & Sylvia communis & - & - & $(2 ; 2)$ & $(1 ; 1)$ \\
\hline Chiffchaff & Phylloscopus collybita & $(15 ; 30)$ & $(5 ; 13)$ & $(10 ; 24)$ & $(4 ; 8)$ \\
\hline Eurasian Nuthatch & Sitta europea & $(7 ; 17)$ & $(9 ; 26)$ & $(4 ; 8)$ & $(2 ; 2)$ \\
\hline Green Woodpecker & Picus viridis & $(1 ; 1)$ & $(3 ; 3)$ & $(0 ; 0)$ & $(2: 2)$ \\
\hline Short-toed Treecreeper & Certhia brachydactyla & $(15 ; 22)$ & $(10 ; 17)$ & $(11 ; 28)$ & $(2 ; 2)$ \\
\hline European Robin & Erithacus rubecula & $(9 ; 17)$ & $(5 ; 8)$ & $(7 ; 12)$ & $(2 ; 6)$ \\
\hline Nightingale & Luscinia megarhynchos & $(4 ; 9)$ & $(1 ; 1)$ & $(5 ; 7)$ & $(0 ; 0)$ \\
\hline Mistle Thrush & Turdus viscivorus & $(6 ; 13)$ & $(8 ; 22)$ & $(4 ; 5)$ & $(3 ; 4)$ \\
\hline
\end{tabular}


Occupancy rate modeling for bird species undergoing climatic changes

Table 2 .

Table 2. Migratory status and biogeographical origins of the selected species. Migratory status: Sedentary (S), Migrant (M) or Partial migrant (P).

\begin{tabular}{lccc}
\hline Species & Migratory status & Global faunistic class & European biogeographical origin \\
\hline Song Thrush & $\mathrm{P}$ & European & Atlantico-continental \\
Common Blackbird & $\mathrm{P}$ & Palearctic & European \\
Whitethroat & $\mathrm{M}$ & Turkestano-european & Atlantico-mediterranean \\
Chiffchaff & $\mathrm{M}$ & Palearctic & Atlantico-continental \\
Eurasian Nuthatch & $\mathrm{S}$ & Palearctic & European \\
Green Woodpecker & $\mathrm{S}$ & European & European \\
Short-toed Treecreeper & $\mathrm{S}$ & European & European \\
European Robin & $\mathrm{P}$ & European & Atlantico-continental \\
Nightingale & $\mathrm{M}$ & European & Atlantico-mediterranean \\
Mistle Thrush & $\mathrm{P}$ & European & Continental \\
\hline \hline
\end{tabular}




\section{Table 3.}

Table 3. Prior mean and CI $95 \%$ of detection probability $\mu_{s a}$ during 1985 and 1987 in Montech forest.

\begin{tabular}{lcccc}
\hline Species & \multicolumn{2}{c}{ Inner forest } & \multicolumn{2}{c}{ Edge forest } \\
& 1985 & 1987 & 1985 & 1987 \\
\hline Song Thrush & $0.8[0.65-1]$ & $0.6[0.3-0.8]$ & $0.8[0.65-1]$ & $0.4[0-0.65]$ \\
Common Blackbird & $0.8[0.65-1]$ & $0.6[0.3-0.8]$ & $0.8[0.65-1]$ & $0.8[0.65-1]$ \\
Whitethroat & - & - & $0.8[0.65-1]$ & $0.8[0.65-1]$ \\
Chiffchaff & $0.8[0.65-1]$ & $0.8[0.65-1]$ & $0.8[0.65-1]$ & $0.8[0.65-1]$ \\
Eurasian Nuthatch & $0.8[0.65-1]$ & $0.8[0.65-1]$ & $0.6[0.3-0.8]$ & $0.6[0.3-0.8]$ \\
Green Woodpecker & $0.6[0.3-0.8]$ & $0.6[0.3-0.8]$ & $0.8[0.65-1]$ & $0.8[0.65-1]$ \\
Short-toed Treecreeper & $0.8[0.65-1]$ & $0.8[0.65-1]$ & $0.6[0.3-0.8]$ & $0.6[0.3-0.8]$ \\
European Robin & $0.8[0.65-1]$ & $0.6[0.3-0.8]$ & $0.8[0.65-1]$ & $0.2[0-0.4]$ \\
Nightingale & $0.6[0.3-0.8]$ & $0.6[0.3-0.8]$ & $0.8[0.65-1]$ & $0.8[0.65-1]$ \\
Mistle Thrush & $0.6[0.3-0.8]$ & $0.6[0.3-0.8]$ & $0.4[0-0.65]$ & $0.4[0-0.65]$ \\
\hline \hline
\end{tabular}




\section{Table 4.}

Table 4. Posterior mean and CI $95 \%$ of $\gamma_{s a}$ for inner and edge regions of Montech forest in 1985 and 1987. Estimates were computed using informative prior on $q_{s a}$.

\begin{tabular}{|c|c|c|c|c|c|c|c|c|}
\hline \multirow[b]{2}{*}{ Species } & \multicolumn{4}{|c|}{ Inner forest } & \multicolumn{4}{|c|}{ Edge forest } \\
\hline & & 1985 & & 1987 & & 1985 & & 1987 \\
\hline Song Thrush & 0.95 & {$[0.91 ; 1]$} & 0.85 & {$[0.68 ; 1]$} & 0.93 & {$[0.89 ; 1]$} & 0.47 & {$[0.06 ; 0.94]$} \\
\hline Common Blackbird & 0.89 & {$[0.77 ; 1]$} & 0.93 & {$[0.77 ; 1]$} & 0.84 & {$[0.78 ; 0.94]$} & 0.76 & {$[0.44 ; 1]$} \\
\hline Whitethroat & & - & & - & 0.16 & {$[0.11 ; 0.28]$} & 0.08 & {$[0.06 ; 0.17]$} \\
\hline Chiffchaff & 0.79 & {$[0.68 ; 0.96]$} & 0.42 & {$[0.23 ; 0.59]$} & 0.63 & {$[0.56 ; 0.78]$} & 0.74 & {$[0.44 ; 1]$} \\
\hline Eurasian Nuthatch & 0.37 & {$[0.32 ; 0.45]$} & 0.68 & {$[0.50 ; 0.86]$} & 0.36 & {$[0.22 ; 0.61]$} & 0.59 & {$[0.22 ; 1]$} \\
\hline Green Woodpecker & 0.11 & {$[0.05 ; 0.32]$} & 0.46 & {$[0.14 ; 0.86]$} & 0.07 & {$[0.05 ; 0.14]$} & 0.49 & {$[0.11 ; 0.83]$} \\
\hline Short-toed Treecreeper & 0.87 & {$[0.73 ; 1]$} & 0.84 & {$[0.64 ; 1]$} & 0.72 & {$[0.61 ; 0.89]$} & 0.59 & {$[0.11 ; 0.94]$} \\
\hline European Robin & 0.51 & {$[0.41 ; 0.68]$} & 0.60 & {$[0.32 ; 0.96]$} & 0.50 & {$[0.39 ; 0.72]$} & 0.57 & {$[0.11 ; 0.94]$} \\
\hline Nightingale & 0.28 & {$[0.18 ; 0.45]$} & 0.19 & {$[0.05 ; 0.50]$} & 0.39 & {$[0.28 ; 0.61]$} & 0.15 & {$[0.06 ; 0.39]$} \\
\hline Mistle Thrush & 0.39 & {$[0.27 ; 0.59]$} & 0.67 & {$[0.45 ; 0.91]$} & 0.59 & {$[0.28 ; 1]$} & 0.75 & {$[0.39 ; 1]$} \\
\hline
\end{tabular}


Table 5.

Table 5. Posterior mean of $\gamma_{s a}$ and CI $95 \%$ for inner and edge regions of Montech forest in 1985 and 1987. Estimates were computed using a non informative prior on $q_{s a}$. Only results differing from the informative approach are presented here.

\begin{tabular}{|c|c|c|c|c|c|c|c|c|}
\hline \multirow[b]{2}{*}{ Species } & \multicolumn{4}{|c|}{ Inner forest } & \multicolumn{4}{|c|}{ Edge forest } \\
\hline & & 1985 & & 1987 & & 1985 & & 1987 \\
\hline Song Thrush & & - & & - & & - & 0.29 & {$[0.06 ; 0.72]$} \\
\hline Common Blackbird & & - & & - & & - & & - \\
\hline Whitethroat & & - & & - & 0.41 & {$[0.11 ; 0.94]$} & 0.42 & {$[0.06 ; 0.94]$} \\
\hline Chiffchaff & & - & & - & & - & & - \\
\hline Eurasian Nuthatch & & - & & - & & - & & - \\
\hline Green Woodpecker & 0.24 & {$[0.05 ; 0.82]$} & 0.56 & {$[0.23 ; 1]$} & 0.25 & {$[0.05 ; 0.82]$} & 0.59 & {$[0.22 ; 1]$} \\
\hline Short-toed Treecreeper & & - & & - & & - & & - \\
\hline European Robin & & - & 0.52 & {$[0.23 ; 0.86]$} & & - & 0.37 & {$[0.11 ; 0.61]$} \\
\hline Nightingale & & - & 0.42 & {$[0.06 ; 0.94]$} & & - & 0.24 & {$[0.05 ; 0.78]$} \\
\hline Mistle Thrush & & - & 0.58 & {$[0.36 ; 0.73]$} & & - & 0.67 & {$[0.33 ; 1]$} \\
\hline
\end{tabular}


Occupancy rate modeling for bird species undergoing climatic changes

Table 6a. Comparison between $\gamma_{s a}$ estimates under unconditional (MacKenzie et al., 2006) and conditional (Dupuis et al., 2010) approaches when a species is not detected, for a non informative and an informative prior on $q_{s a}$ : case of the Green Woodpecker in edge region of

Montech forest in 1985. $J=T=18$.

\begin{tabular}{lrlrr}
\hline & \multicolumn{3}{c}{ Unconditional approach } & \multicolumn{2}{c}{ Conditional approach } \\
\hline Non informative prior & 0.13 & {$[0 ; 0.68]$} & 0.25 & {$[0.05 ; 0.82]$} \\
Informative prior & 0.02 & {$[0 ; 0.11]$} & 0.07 & {$[0.05 ; 0.14]$} \\
\hline
\end{tabular}

Table 6b. Comparison between $\gamma_{s a}$ estimates under unconditional (MacKenzie et al., 2006) and conditional (Dupuis et al., 2010) approaches when a species is not detected, for a non informative and an informative prior on $q_{s a}$ : case of the Nightingale in edge region of Montech forest in 1987. $J=18, T=6$.

\begin{tabular}{lrlrc}
\hline & \multicolumn{3}{c}{ Unconditional approach } & \multicolumn{2}{c}{ Conditional approach } \\
\hline Non informative prior & 0.20 & {$[0 ; 0.78]$} & 0.24 & {$[0.05 ; 0.78]$} \\
Informative prior & 0.12 & {$[0 ; 0.39]$} & 0.15 & {$[0.05 ; 0.39]$} \\
\hline \hline
\end{tabular}

